\title{
História da psiquiatria no Brasil: uma revisão da produção historiográfica ( 2004-2009)
}

\section{History of psychiatry in Brazil: a review of historiographical production (2004-2009)}

\section{Andrea de Alvarenga Lima}

Mestranda em Psicologia da Universidade Federal do Paraná - UFPR, Curitiba, PR, Brasil

\section{Adriano Furtado Holanda*}

Professor Adjunto da Universidade Federal do Paraná - UFPR, Curitiba, PR, Brasil

\begin{abstract}
RESUMO
As recentes transformações, ocasionadas pela Reforma Psiquiátrica, ensejam o questionamento sobre a forma como a História da Psiquiatria é estudada nos dias de hoje. Este artigo faz uma revisão dos trabalhos científicos recentes e identifica as principais perspectivas e recortes adotados sobre 0 assunto. Foram selecionados 69 estudos, entre artigos, teses e dissertações, que atenderam aos seguintes critérios: estarem relacionados à história do campo "psi" (Psiquiatria, Psicologia e Psicanálise), serem publicados no Brasil entre 2004 e 2009 e se utilizarem do método historiográfico. $\mathrm{Na}$ revisão efetuada, são analisadas as tendências contemporâneas, em relação a: balizas cronológicas, delimitação geográfica dos estudos, fontes utilizadas, temáticas priorizadas e lugar de produção. Constata-se que, a maior parte das pesquisas, produzida e publicada no eixo Rio/São Paulo, está embasada em documentos escritos, e concentra sua atenção, preferencialmente, na constituição do saber psiquiátrico na Região Sudeste. A observação de tais recortes torna evidente a existência de lacunas na narrativa histórica.
\end{abstract}

Palavras-chave: História, Psiquiatria, Loucura, Hospital psiquiátrico, Historiografia.

\begin{abstract}
The recent changes brought about by the Psychiatric Reform invite inquiry into how the History of Psychiatry is being studied today. This article reviews recent scientific papers and identifies the main perspectives and limits established by historians on the subject. Sixty nine papers were selected, including articles, theses, and dissertations, which met the following criteria: be related to the history of the "psy" sciences (Psychiatry, Psychology and Psychoanalysis), be published in Brazil between 2004 and 2009, and use the historiographic method. In this review, contemporary trends are analyzed, in relation to: time periods, the geographical boundaries of the studies, and the methodological approaches employed. The review showed that most researches are produced and published in Rio
\end{abstract}


de Janeiro and São Paulo, rely on written documents and focus their attention on the constitution of the psychiatric knowledge in the Southeast of Brazil. Considering the data collected, gaps in the historical narrative are identified.

Keywords: History, Psychiatry, Madness, Psychiatric hospital, Historiography.

\section{I ntrodução}

Em tempos de reforma psiquiátrica, a luta pela desinstitucionalização da loucura e pelo "fim dos manicômios", trouxe a público uma série de discussões que enfatizaram, tanto nos meios acadêmicos quanto na sociedade em geral, a noção da constituição histórica da doença mental e dos saberes e práticas "psi".

A forma como esse campo se constitui enquanto objeto para a História tem se modificado e a História da Psiquiatria tem sido contada por ângulos diversos. No Brasil, os estudos sobre o tema da História da Medicina em geral, podem ser categorizados em três momentos diferentes. Num primeiro período, os textos - produzidos primordialmente por médicos - caracterizavam-se pela narrativa descritiva e esquemática que buscava apresentar o triunfo da ciência moderna e construir uma visão enobrecedora da classe médica. Os trabalhos historiográficos que surgem num segundo momento, a partir da década de 1970, foram marcados por proposições teóricas, elaboradas por Foucault, mescladas, no Brasil, a um marxismo gramsciano. A história, constituída sob essa ótica, denunciava o caráter de instrumento técnico-científico da Medicina, utilizado pelo Estado para a disciplinarização da população e explicitava estratégias, através das quais, a classe médica se estabelecia como um novo tipo de saber/poder. (EDLER, 1998; JABERT, 2008)

Segundo Edler (1998), mais recentemente, a partir da década de 1990, começam a ser produzidas perspectivas que, seja aprofundando aspectos específicos dos trabalhos foucaultianos da geração anterior, seja adotando outras propostas teóricometodológicas, valorizam o maior controle das hipóteses históricas e a escolha de temas menos abrangentes. Essa nova historiografia se caracteriza por um maior rigor metodológico no trabalho com as fontes, somado á busca de novos objetos e abordagens.

Fazer uma reflexão sobre a produção historiográfica relativa à constituição da Psiquiatria e campo da saúde mental conduz de imediato, a citar alguns trabalhos clássicos sobre o caráter histórico das formas de compreensão da loucura. No âmbito da própria Psiquiatria, destaca-se a perspectiva histórica estabelecida pelas reflexões de Thomas Szasz (1978), em A Fabricação da Loucura, onde o autor faz uma analogia que traça paralelos entre as práticas psiquiátricas modernas e os métodos medievais de identificação e punição de feiticeiras. 
A temática da instituição psiquiátrica remete, também, necessariamente, à obra do filósofo Michel Foucault (1987, 2006a, 2006b), que se apresenta como referência paradigmática ao reformular a compreensão da experiência contemporânea da doença mental a partir da explicitação da sua constituição histórica. Tendo tratado a relação entre loucura e saber por uma abordagem alternativa para a nova história da cultura, Foucault mudou o foco tradicional de estudo da sociedade em si mesma, para a problematização das condições de produção de um discurso psiquiátrico e análise das relações entre o discurso/saber e os dispositivos disciplinares e técnicas de poder que organizam 0 tratamento dos loucos (O'BRIEN, 2006).

No Brasil, embasados na perspectiva foucaultiana, vários estudos importantes sobre a história do saber psiquiátrico e das instituições asilares centraram suas reflexões em torno do desvendamento da maneira como as condutas sociais tornam-se patológicas e subordinadas aos saberes médico e psicológico, através da inserção da Psiquiatria nas engrenagens do poder. Tais pesquisas - cuja delimitação cronológica foca o final do século XIX e começo do século $X X$, momento da emergência do discurso da medicina psiquiátrica na sociedade brasileira - se debruçam sobre várias das primeiras instituições psiquiátricas brasileiras, e analisam as estratégias de controle dos indivíduos e das populações, adotadas pela Medicina Social em geral e pela Psiquiatria em particular.

Nessa linha de pesquisa, cabe destacar a obra de Roberto Machado, Angela Loureiro, Rogério Luz e Kátia Muricy (1978), Danação da Norma, um dos textos fundamentais sobre a ampliação dos limites da Medicina e constituição da Psiquiatria, no Brasil. Estudos sistemáticos relativos a instituições psiquiátricas específicas foram desenvolvidos por Maria Clementina Pereira Cunha (1986), sobre o Asilo Juquery, em São Paulo e, por Yonissa Wadi (2002), a respeito do Hospital São Pedro, em Porto Alegre.

Quer pelo pioneirismo de suas contribuições, quer pela influência que exerceram nos debates nas décadas posteriores, merecem destaque, também, as obras de Jurandir Freire Costa (2007) e Isaias Pessotti (1995, 1996, 1999).

É, assim, no intuito de perceber as características distintivas da historiografia recente, que o presente trabalho se volta para destacar o perfil atual das pesquisas na historiografia contemporânea, com respeito à temática do surgimento, consolidação e trajetória do saber psiquiátrico no Brasil. O exame dessa produção recente possibilitará evidenciar as tendências presentes, tanto nas escolhas metodológicas, quanto na própria constituição dos objetos da pesquisa histórica em relação às delimitações cronológicas, espaciais e temáticas. Embora reconheçamos a necessidade de uma discussão epistemológica, um levantamento abrangente dessas perspectivas 
epistêmicas - implícitas ou explícitas - que estão no bojo da discussão do processo de constituição do saber psiquiátrico no Brasil e que alicerçam os debates em torno da desinstitucionalização e da reforma psiquiátrica no país, extrapolam os objetivos deste artigo. Desta feita, estaremos centrados em aspectos objetivos da pesquisa historiográfica contemporânea, associados a esse debate.

\section{Método}

A pesquisa e localização dos trabalhos analisados foram efetuadas, inicialmente, através de uma busca sistemática em bases de dados virtuais, de artigos publicados em periódicos científicos, capturados por meio dos descritores: "história + psiquiatria", "história + loucura", "história + hospital psiquiátrico" e "história + reforma psiquiátrica", nos sites da BVS-Psi (Biblioteca Virtual em Saúde Psicologia) - www.bvs-psi.org.br, do Scielo (Scientific Electronic Library Online - Brazil) - http://www.scielo.br e do Pepsic (Periódicos Eletrônicos em Psicologia) - www.pepsic.bvs-psi.org.br. Outras referências, incluídas na revisão, foram obtidas em busca manual ao site da revista Mnemosine (www.mnemosine.cjb.net), e através de consultas a dissertações, teses e livros. Além destes sítios, foi ainda consultado o arquivo da revista Psychiatry on line Brasil, que mantém uma seção contínua sobre a história da Psiquiatria.

Os critérios de inclusão de trabalhos para esta pesquisa foram: local de publicação (território nacional); data de publicação (sendo escolhido o período compreendido entre os anos de 2004 e 2009, como forma de organizar a produção mais recente); relação do texto com a história do campo "Psi" (Psiquiatria, Psicologia e Psicanálise, mas mantendo relação direta com a temática da saúde mental) e a utilização do método historiográfico, ou seja, os trabalhos selecionados não poderiam se limitar a uma revisão do conhecimento histórico anteriormente produzido, mas deveriam se utilizar da fundamentação teórico-metodológica específica da disciplina.

Para fins de seleção dos trabalhos, adotou-se a definição de método historiográfico proposta por Aróstegui (2006, p. 455), segundo a qual este se caracteriza por estudar os fenômenos, sempre, em seu comportamento temporal, apresentando as seguintes peculiaridades distintivas: 1) a natureza de suas fontes de informação (necessariamente indiretas e mediadas por vestígios, restos ou testemunhos); 2) a perspectiva temporal (dada a necessidade de captar o processo e construir cronologias); e, 3) a apreciação da singularidade e unicidade de todo devir histórico, acompanhada, paradoxalmente, da generalidade do histórico, enquanto qualidade das coisas.

Selecionados os resumos que preencheram esses critérios, os textos detectados foram recuperados na íntegra e analisados em relação à 
delimitação cronológica e geográfica dos objetos de estudo, às fontes utilizadas, às temáticas pesquisadas e ao lugar de produção.

Foram identificados e avaliados um total de 69 trabalhos, assim distribuídos: 57 artigos publicados em periódicos científicos, sete teses de doutorado, cinco dissertações de mestrado. Devido a dificuldades na distribuição e comercialização por parte de algumas das editoras, foi impossível ter acesso a todas as referências publicadas no formato livro, sendo a categoria excluída do estudo.

\title{
Resultados
}

Balizas Cronológicas

A idéia da História como uma ciência que constrói um conhecimento dos eventos no tempo, é bastante difundida e aceita (ARÓSTEGUI, 2006; CERTEAU, 2008; ELIAS, 1998; FUNARI; SILVA, 2008). A respeito da cronologia na operação historiográfica, Certeau (2008), afirma:

\begin{abstract}
Inicialmente, a historiografia separa seu presente de um passado. Porém, repete sempre o gesto de dividir. Assim sendo, sua cronologia se compõe em 'períodos' (por exemplo, Idade Média, História Moderna, História Contemporânea). (...) Logo, o corte é o postulado da interpretação (que se constrói a partir de um presente) e seu objeto (as divisões organizam as representações a serem interpretadas) (p. 15).
\end{abstract}

O lapso cronológico recortado pelos historiadores, nos trabalhos examinados, foi agrupado em três grandes períodos, relacionados à construção dos modelos de atenção à saúde mental no Brasil: 1) do início do período colonial até 1889 - período de instalação das primeiras instituições para alienados no Brasil; 2) entre 1890 e 1966 - período de constituição e consolidação da Psiquiatria no país; 3) de 1967 até os dias de hoje - período em que surgem as discussões sobre a assistência nos hospitais psiquiátricos públicos e que se implementa a reforma psiquiátrica.

O primeiro período, que se estende desde a instalação da administração colonial portuguesa no Brasil, até a proclamação da República, foi objeto de um total de 12 estudos ( $17,3 \%$ da amostra). Desse grupo, somente as discussões de Oda $(2007,2008)$, sobre a nostalgia dos escravos no Brasil, retroagem ao século XVIII. Os demais enfocam o período mais recente do Brasil Império, momento da emergência do alienismo e das primeiras instituições asilares destinadas ao internamento dos loucos.

A grande maioria dos trabalhos concentra sua atenção num segundo momento, entre 1890 e 1966, quando se processa a instalação e a 
consolidação de uma Psiquiatria médica e de uma tecnologia asilar no país. Esse período é tomado por objeto de um total de 42 trabalhos, $60,8 \%$ da amostra.

Um terceiro grupo de trabalhos analisados, composto de nove textos, ou $13 \%$ da amostra, objetiva a historicização do percurso mais recente da assistência psiquiátrica, caracterizado pelo movimento de Reforma Psiquiátrica, que se encontra, até os dias de hoje, em processo de implantação e é tema de acirrados debates. Para a categorização dos trabalhos, definiu-se por baliza cronológica o contexto que ensejou as primeiras discussões sobre esse movimento, que surge, a partir do ano de 1967, quando da criação do INPS (Instituto Nacional de Previdência Social), relacionado a um novo modelo de assistência médica que acelera o processo de privatização dos hospitais psiquiátricos (PAULIN; TURATO, 2004, p. 242).

Os trabalhos de Carvalho e Amparo (2006), Dalgalarrondo (2007), Jacó-Vilela, Espírito Santo e Pereira (2005), Jacó-Vilela et al. (2004), Messas (2008) e Piccinini e Oda (2006), ou seja, 8,6\% da amostra, não se enquadraram nas categorias acima por estabelecerem, para seus estudos, lapsos cronológicos mais longos que os recortados nessa análise. 


\begin{tabular}{|c|c|c|c|}
\hline Até 1889 & De 1890 a 1966 & A partir de 1967 & Não se enquadr am \\
\hline Gonģtves e Edler (2009) & Ameida, Oda e Dalgalarrondo (2007) & Borges $(2006,2007)$ & Carvalho e Amparo (2006) \\
\hline Oda $(2005,2007,2008)$ & Almeida (2007) & $\operatorname{Diaz}(2008)$ & Dalgalarrondo (2007) \\
\hline Oda e Dalgalarrondo $(2004,2005)$ & Almeida $(2006,2008)$ & Paiva e Yamamoto (2007) & $\begin{array}{l}\text { Jacó-Vilela, Espírito Santo e Pereira } \\
\qquad(2005)\end{array}$ \\
\hline Oiveira e Oda (2008) & Arantes (2007) & Paulin e Turato (2004) & Jacó-Vilela et al (2004) \\
\hline Rios $(2008)$ & Araújo, Moreira e Rodha (2009) & Pereira (2004) & Messas (2008) \\
\hline Rocha, Tranquilli e Lepikso (2004) & Boarini (2007) & Pombo (2007) & Plccinini e Oda (2006) \\
\hline Souza e Jaco-Vlela $(2008)$ & Borenstein et al. $(2007)$ & Vasconcelos $(2004)$ & \\
\hline Tarso (2008) & Castro e Várgas (2005) & Wadi $(2009)$ & \\
\hline \multirow[t]{24}{*}{ Vasconcellos e Vasconcellos (2007) } & Costa e Fonseca (2007) & & \\
\hline & Dalgalarrondo, Gutman e Oda (2007) & & \\
\hline & Engel, $(2008)$ & & \\
\hline & Facchinetti e Venando (2006) & & \\
\hline & Facthinetti, Ribeiro e Munhoz (2008) & & \\
\hline & Gutman (2007) & & \\
\hline & Jabert $(2005,2008)$ & & \\
\hline & Jacobina $(2004)$ & & \\
\hline & Jacobina e Gelman (2008) & & \\
\hline & Jaeger, Fonseca e Sanches (2006) & & \\
\hline & Magnani (2004) & & \\
\hline & Melo $(2004)$ & & \\
\hline & Oda e Picanini (2005) & & \\
\hline & Oryama (2006) & & \\
\hline & Pereira (2005) & & \\
\hline & Pereira e Gutman (2007) & & \\
\hline & Ribeiro (2006) & & \\
\hline & Santos (2005, 2006a, 2006b) & & \\
\hline & Silva $(2008,2009)$ & & \\
\hline & Silveira (2008a, 2008b, 2009) & & \\
\hline & Venancio $(2004,2005)$ & & \\
\hline & Venandio e Facchinetti (2005) & & \\
\hline & Vidal $e$ Amorin (2008) & & \\
\hline & Wadi (2004,2006, 2006) & & \\
\hline 12 trabalhos $(17,3 \%)$ & 42 trabalhos $(60,8 \%)$ & 9 trabalhos $(13 \%)$ & 6 trabalhos $(8,6 \%)$ \\
\hline
\end{tabular}

Delimitação espacial

A prática historiográfica, em função de seu interesse pela singularidade do devir, pela especificidade dos eventos, é, caracteristicamente, localizada. Ainda que muitos dos estudos da amostra, mais voltados para uma história das idéias, não objetivem assinalar contextos territoriais - um Estado, uma Região ou um Município -, a análise da demarcação geográfica das pesquisas, seja ela indicada claramente ou inferida a partir de seus personagens, permite perceber os espaços sócio-históricos cujas peculiaridades nos processos de instalação, desenvolvimento e Reforma Psiquiátrica têm sido privilegiados pelos estudos contemporâneos. 
Diferentemente dos estudos que se voltam para autores específicos ou experiências particulares, um total de 09 trabalhos (13\%) tomam a nação brasileira como um todo, enquanto unidade de análise. Considerando-se trabalhos que abordaram contextos regionais plurais em mais de uma categoria, constatou-se que as instituições psiquiátricas e as discussões da classe médico-psiquiátrica, no Rio de Janeiro, foram objeto para um total de 26 pesquisas $(37,6 \%$ da amostra). O quadro da Psiquiatria no Rio Grande do Sul é abordado em 13 trabalhos da amostra (18,8\%), e a História da Psiquiatria em São Paulo é enfocada por um total de 9 trabalhos (13\%). A Psiquiatria em Minas Gerais é discutida em oito trabalhos $(11,5 \%)$ e 7 trabalhos $(10,1 \%)$ tratam de pensadores ou instituições da Bahia. Existem quatro referências à Psiquiatria no Paraná $(5,7 \%)$, e também quatro sobre Pernambuco $(5,7 \%)$.

A única referência à História da Psiquiatria no Maranhão e Pará, está presente no trabalho de Oda e Dalgalarrondo (2005). A discussão proposta por Borenstein et al. (2007) refere-se a Santa Catarina, a de Jabert (2005) ao Espírito Santo, e a de Paiva e Yamamoto (2007) ao Rio Grande do Norte.

Não foram encontrados trabalhos sobre a região Centro-Oeste, nem sobre os estados de Sergipe, Alagoas, Paraíba, Ceará, Piauí, Tocantins, Amapá, Roraima, Amazonas, Rondônia ou Acre.

\section{As Fontes Utilizadas}

A natureza específica da pesquisa historiográfica, que perfaz um corte entre o presente do pesquisador e um passado, determina que os fatos estudados somente possam ser captados pela inferência, a partir de restos ou vestígios: as fontes da história (Aróstegui, 2006, p. 490).

Nos trabalhos analisados, as tramas narradas se alimentaram de informações historiográficas obtidas através de fontes bastante heterogêneas. A grande maioria das pesquisas se utiliza, exclusivamente, da observação documental (60 trabalhos, 86,9\% da amostra) verificando-se, também, em menor escala (seis trabalhos, $8,6 \%$ da amostra), a utilização combinada de observação documental e depoimentos, sendo que apenas três trabalhos se basearam, exclusivamente, em depoimentos orais (4,3\% da amostra).

Dentre a documentação consultada, encontram-se arquivos públicos e legislação, imprensa, registros médicos e psiquiátricos (teses, artigos publicados em periódicos especializados, documentos clínicos, etc.), arquivos de instituições psiquiátricas, literatura ficcional, cartas escritas pelos loucos e plantas arquitetônicas de instituições asilares. A tabela abaixo indica quais as fontes escritas foram priorizadas pelos autores: 


\begin{tabular}{|c|c|}
\hline $\begin{array}{l}\text { Arquivos públicos e } \\
\text { legislação }\end{array}$ & $\begin{array}{l}\text { Araúja, Moreira e Rocha (2009), Gonçalves e Edle (2009), Jabert (2005), } \\
\text { Jacobina (2004), Maqnani (2004), Messas (2008), Oda e Dalqalarrondo } \\
\text { (2004, 2005), Ouyame (2006), Paiva e Yamemoto (2007), Paulin e Turato } \\
\text { (2004), Piccinini e Oda (2006), Pereira (2004), Pombo (2007), Silva (2008, } \\
2009) \text {, Vida e Amorin (2008) e Wadi (2009). A imprensa fai utilizada por } \\
\text { Almeida (2007), Araújo, Moreira e Rocha (2009), Jabert (2008), Jacobina e } \\
\text { Gelman (2008), Magnani (2004), Oliveira e Oda (2008) Pombo (2007), } \\
\text { Ribeiro (2006), Silva (2008, 2009), Silveira 2008a), Tarso (2008) e } \\
\text { Vasconcellos e Vasconcellos (2007). }\end{array}$ \\
\hline $\begin{array}{l}\text { Registros Médicos e } \\
\text { Psiquiátricos }\end{array}$ & $\begin{array}{l}\text { Almeida, Oda e Dalgalarrondo (2007), Almeida (2006, 2008), Boarini (2007), } \\
\text { Barges (2007), Carval ho e Anparo (2006), Costa e Fonseca (2007), } \\
\text { Dalgalarrondo (2007), Dalgalarrondo, Gutman e Oda (2007), Engel (2008), } \\
\text { Facchinetti, Ribero, e Munoz (2008), Facchinetti e Venâncio (2006), Gutman } \\
\text { (2007), Jabert (2008), Jacó-Vilela (2004), Jacó-Vilela et al (2004), Jacó- } \\
\text { Vilela, Espírito Santo e Pereira (2005), Jacobina e Gelman (2008), Melo } \\
\text { (2004), Oda (2005, 2007, 2008), Oda e Dalgalarrondo (2004), Oda e } \\
\text { Piccinini (2005), Ouyame, (2006), Paiva e Yamamoto (2007), Pereira (2005), } \\
\text { Pereira e Gutman (2007), Ribaro (2006), Rios (2008), Rocha, Tranquilli e } \\
\text { Lepikson (2004), Santos (2006a), Silva (2008, 2009), Silveira (2008a, } \\
\text { 2008b, 2009), Souza e Jacó-Vilda (2008), Vasconcelos (2004), Venancio } \\
\text { (2004, 2005), Venancio e Facchinetti (2005) e Vidal e Amorin (2008). }\end{array}$ \\
\hline $\begin{array}{l}\text { Arquivos de } \\
\text { Instituicões } \\
\text { psiquiátricas }\end{array}$ & $\begin{array}{l}\text { Almeida (2007), Borqes (2007), Jaeqer, Fonseca e Sanches (2006), Maqnani } \\
\text { (2004), Ouyame (2006), Rios (2008), Silva (2008, 2009), Vasconcellos e } \\
\text { Vasconcellos (2007) e Wadi (2006). }\end{array}$ \\
\hline Literatu & Arantes (2007), Diaz (2008), Santos (2005, 2006b) e Silva (2008, 2009). \\
\hline
\end{tabular}

\begin{tabular}{|c|c|}
\hline Cartas & Santos $(2005,2006 a)$ e Wadi $(2004,2005)$ \\
\hline $\begin{array}{l}\text { Plantas } \\
\text { arquitetônicas de } \\
\text { instituições asilares }\end{array}$ & Magnani (2004) e Oryama, (2006) e Ribeiro (2006). \\
\hline Testemunhos orais & $\begin{array}{l}\text { Bar ges (2007), Diaz (2008), Paiva e Yamemoto (2007), Pombo (2007), } \\
\text { Ribeiro (2006), Venancio (2005), Borenstein et al. (2007), Borges (2006), } \\
\text { Castro e Vargas (2005) e Rangel (2006) }\end{array}$ \\
\hline
\end{tabular}

História Oral pode ser tomada, dependendo da sua utilização, enquanto método de investigação cientifica, fonte de pesquisa ou técnica de coleta de depoimentos (ALBERTI, 2008, p. 17). Testemunhos orais, gravados com o emprego da metodologia da História Oral, foram utilizados, em conjunto com outras fontes, por Borges (2007), Diaz (2008), Paiva e Yamamoto (2007), Pombo (2007), Ribeiro (2006), Venancio (2005). Somente os trabalhos de Borenstein et al. (2007) e Borges (2006), Castro e Vargas (2005) e Rangel (2006) elegeram a realização de testemunhos como fonte exclusiva de informação histórica.

A constatação da multiplicidade das fontes utilizadas pela historiografia contemporânea aponta para o aspecto plural das perspectivas através das quais a Psiquiatria se constitui como objeto 
histórico, bem como para a dinamicidade de aspectos metodológicos envolvidos.

Temáticas de Estudo

O historiador Paul Veyne (2008) em uma reflexão a respeito da escrita da História, comenta que "como o romance, a História seleciona, simplifica, organiza, faz com que um século caiba numa página, e essa síntese da narrativa é tão espontânea quanto a da nossa memória, quando evocamos os dez últimos anos que vivemos" (p. 18). Nessa perspectiva, a análise das temáticas, privilegiadas pelos historiadores, é um indicativo do que o momento presente valoriza e escolhe lembrar.

A análise dos temas tratados nesses trabalhos revela uma ampla diversidade de proposições. Foram identificadas quatro principais categorias temáticas: 1) constituição do pensamento "psi"; 2) história institucional e o processo de institucionalização dos loucos; 3) a Psiquiatria e processos de subjetivação; e, 4) a Reforma Psiquiátrica.

A categoria "constituição do pensamento psi" englobou 30 trabalhos (43,4\% da amostra), cuja temática se voltou para o esclarecimento de como as teorias, no âmbito das disciplinas "Psi" - Psiquiatria, Psicologia e Psicanálise -, influenciadas por diferentes escolas de pensamento, se desenvolveram, criativamente, e se articularam, na história brasileira, com processos e projetos políticos e sociais mais abrangentes.

Nessa perspectiva, textos originais, debates e autores representativos do processo de constituição desses saberes são retomados, analisados, contextualizados e postos em relação com a conformação de valores e questões que atravessaram as transformações ideológico-sociais da sociedade brasileira. Dentre esses fundadores do campo "psi", tomados como objeto de estudo, o mais discutido é Juliano Moreira [1873-1933] (JACOBINA; GELMAN, 2008; ODA; PICCININI， 2005; SILVEIRA, 2008b; VENANCIO， 2004， 2005; VENANCIO; FACCHINETTI, 2005). Outros autores analisados são: Luiz Vicente De-Simoni [1792-1881] (ODA; DALGALARRONDO, 2004), Manoel Ignácio de Figueiredo Jaime [?-?] (SOUZA; JACÓVILELA, 2008), José Francisco Xavier Sigaud [1796-1856] (ODA, 2005), J osé Martins da Cruz Jobim [1802-1878] (ODA, 2005), Franco da Rocha [1864-1933] (ALMEIDA, 2008). Henrique Belford Roxo [1877-1969] (FACCHINETTI; VENANCIO, 2006), Ulisses Pernambucano [1892-1943] (MELO, 2004; PEREIRA, 2005), Ozório Cezar [1895-1980] (DALGALARRONDO; GUTMAN; ODA, 2007), Dyonélio Machado [1895-1985] (ALMEIDA, 2006), Emílio Mira y Lopez [1896-1964] (J ACÓ-VILELA, 2004), Roger Bastide [1898-1974] (DALGALARRONDO; GUTMAN; ODA, 2007), Hermelino Lopes Silveira [1899-1971] (SILVEIRA, 2008a, 2008b, 2009), Arthur Ramos [1903- 
1949] (GUTMAN, 2007; JACÓ-VILELA, 2004; PEREIRA; GUTMAN, 2007), Nise da Silveira [1905-1999] (CARVALHO; AMPARO, 2006).

Também são tematizadas tanto os Archivos da Liga Brasileira de Higiene Mental (BOARINI, 2007), quanto as teses médicas do século XIX até princípios do XX, que evidenciavam preocupação com fatores psicológicos, e são defendidas na Faculdade de Medicina da Bahia (ROCHA; TRANQUILLI; LEPIKSON, 2004) e na Faculdade de Medicina do Rio de Janeiro (JACÓ-VILELA; ESPÍRITO SANTO; PEREIRA, 2005) bem como duas questões que foram foco de debates ao longo da trajetória de constituição do saber psiquiátrico: o embate entre Psiquiatria e Religião (ALMEIDA; ODA; DALGALARRONDO, 2007; DALGALARRONDO, 2007; ALMEIDA, 2007; JABERT, 2008) e Escravidão e Psicopatia no Brasil (ODA, 2007, 2008; OLIVEIRA; ODA, 2008).

$\mathrm{Na}$ segunda categoria, "história institucional e o processo de institucionalização dos loucos", foram incluídos 21 trabalhos (30,4\% da amostra). Alguns deles, como os artigos de Jabert (2005), Messas (2008) e Piccinini e Oda (2006) desenvolvem temáticas relacionadas à forma como se desenvolveram as políticas públicas de atenção ao louco. Outros propõem análises voltadas para a reconstrução da trajetória de instituições que se dedicaram ao atendimento dos loucos (como asilos, sanatórios, escolas de Medicina e Enfermagem, hospícios, hospitais psiquiátricos, pavilhões-escola, colônias agrícolas, centros de reabilitação), explicitando tanto as práticas assistenciais e os preceitos médico-científicos empregados no cuidado da população interna, quanto os significados desses estabelecimentos, nos seus diferentes contextos histórico-sociais. É o caso dos textos de Araújo, Moreira e Rocha (2009); Borenstein, Padilha, et al. (2007); Borges (2006, 2007); Castro e Vargas (2005); Costa e Fonseca (2007), Gonçalves e Edler (2009); Jacó-Vilela et al. (2004); Jacobina e Gelman (2008): Jaeger, Fonseca e Sanches (2006); Magnani (2004); Oda e Dalgalarrondo (2005); Ouyama (2006); Ribeiro (2006); Rios (2008); Silva (2008, 2009); e Vidal e Amorim (2008).

Nas pesquisas do grupo temático "Psiquiatria e processos de subjetivação", a tônica se coloca no desvelamento das experiências subjetivas da loucura, e nas relações e sentidos que, no contexto psiquiátrico, se constroem entre indivíduo e sociedade. Arantes (2007), Engel (2008), Facchinetti, Ribeiro e Munoz (2008), Santos (2005, 2006a, 2006b), Vasconcellos e Vasconcellos (2007) e Wadi (2005) se dedicam a esse tipo de tema, num total de 11 trabalhos $(15,9 \%)$.

Na última categoria, Diaz (2008), Paiva e Yamamoto (2007), Paulin e Turato (2004), Pereira (2004), Pombo (2007), Vasconcelos (2004) e Wadi (2009) abordaram as recentes transformações no modelo brasileiro de saúde mental e os embates e questionamentos 
suscitados pela Reforma Psiquiátrica, perfazendo um total de sete trabalhos $(10,1 \%)$.

\section{O Lugar de Produção}

Não se pode compreender a pesquisa historiográfica desarticulada de seu lugar de produção, ou seja, do meio no qual ela é elaborada que a circunscreve por determinações peculiares. Certeau (2008) salienta que "é em função deste lugar que se instauram os métodos, que se delineia uma topografia de interesses, que os documentos e as questões, que lhes são propostas, se organizam" (p. 67).

No intuito de localizar a produção analisada, dois itens foram observados. Primeiro, foi considerada a inscrição dos autores num campo disciplinar, através da identificação da sua formação acadêmica de base. Segundo, a vinculação institucional dos trabalhos foi avaliada, sendo que, para os trabalhos acadêmicos, foram considerados o curso e a instituição de ensino onde foram desenvolvidos, e, em relação aos artigos, observou-se o periódico que os publicou.

Os autores dos 69 trabalhos compõem um universo de 71 indivíduos. Dentre eles, 28 se graduaram em Psicologia (39,4\%), 15 em Medicina $(21,1 \%), 12$ em História $(16,9 \%), 10$ em enfermagem $(14,8 \%)$, quatro em Ciências Sociais $(5,6 \%)$ e um em Filosofia $(1,4 \%)$.

Os trabalhos acadêmicos analisados estão, em sua grande maioria $(83,3 \%)$, vinculados a cursos de pós-graduação em História. É o caso das cinco dissertações da amostra, desenvolvidas por Borges (2007), da Universidade Federal do Rio Grande do Sul, Magnani (2004) e Silva (2008), da Casa de Oswaldo Cruz - Fiocruz, e Pombo (2007) e Ribeiro (2006), da Universidade Federal de Uberlândia. E, também, de cinco das sete teses, incluindo os trabalhos de Almeida (2007) da Unicamp, Diaz (2008) e Jabert (2008) da Casa de Oswaldo Cruz Fiocruz; Oyuama (2006) da Universidade Federal do Paraná, e Santos (2005) da Universidade Federal do Rio Grande do Sul. As exceções são as teses de Doutorado na área de Saúde Pública, defendida por Rosemary Corrêa Pereira (2004), na Escola Nacional de Saúde Pública Sérgio Arouca, e em Educação, por Renato Diniz Silveira (2008), na Universidade Federal de Minas Gerais.

O exame dos meios de veiculação dos artigos mostrou que a Revista Latinoamericana de Psicopatologia Fundamental, vinculada ao Programa de Estudos Pós-Graduados em Psicologia Clínica da Pontifícia Universidade Católica de São Paulo, é o periódico que concentra o maior número de publicações na área. No período considerado, foram publicados um total de vinte trabalhos (35\% dos artigos).

Doze artigos (21\% deles) foram veiculados pelo periódico História, Ciências, Saúde - Manguinhos, da Casa de Oswaldo Cruz, unidade 
da Fundação Oswaldo Cruz dedicada à documentação, pesquisa em história das ciências e da saúde e divulgação científica, com sede no Rio de Janeiro.

Por sua vez, a Revista Mnemosine, publicação do Departamento de Psicologia Social e Institucional do Instituto de Psicologia da UERJ, foi responsável por seis artigos (10,5\%) e a revista História UNISINOS, do programa de Pós-Graduação em História da Universidade do Vale do Rio dos Sinos, em São Leopoldo, Rio Grande do Sul, publicou três $(5,2 \%)$. As revistas Memorandum, vinculada ao Departamento de Psicologia da Faculdade de Filosofia e Ciências Humanas da Universidade Federal de Minas Gerais e ao Departamento de Psicologia e Educação da Faculdade de Filosofia, Ciências e Letras de Ribeirão Preto/USP, Revista de Psiquiatria Clínica (USP-SP) e a Revista Eletrônica Saúde Mental Álcool e Drogas publicaram dois trabalhos cada $(3,5 \%)$.

Cabe aqui um destaque especial à publicação Psychiatry on line Brasil. Esta revista traz no corpo do periódico uma seção - ou "coluna", como se apresenta - sobre a "História da Psiquiatria". Talvez exatamente por se constituir numa "coluna", não tenha, em sua definição, uma preocupação estrita com o desenvolvimento de longos estudos. Mesmo assim publica importantes apontamentos para a construção de uma história da saúde mental no Brasil com abordagens diversas a temas tais como: a constituição da Associação Brasileira de Psiquiatria (PICCININI, 2010); tratamentos morais e jurídico-assistenciais desde os jesuítas (OLIVEIRA; RÊGO; 2009); primeiros registros sobre atendimentos psiquiátricos no Brasil (OLIVEIRA; RÊGO; SILVA, 2007) ou em Minas Gerais (BOTTI; CASTRO; COTTA, 2009); relatórios de importantes hospitais, como o São Pedro, de Porto Alegre (PICCININI, 2009a, 2009b). Entretanto, mesmo apresentando-se como uma inegável fonte de dados históricos sobre o tema a que dissertamos, incluímos apenas uma referência na estatística final de nosso estudo (PICCININI; ODA, 2006).

Os periódicos Cadernos de Saúde Pública (COC - RJ), Estudos Históricos (CPDOC/FGV - RJ), Gazeta Médica da Bahia (FMB/UFBA BA), Interações (São Marcos - SP), Physis: Revista de Saúde Pública (IMS/UERJ - RJ), Psychiatry on line Brasil, Revista Baiana de Saúde Pública (SES - BA), Revista Brasileira de Enfermagem (ABEn), Tempo e Argumento (UDESC - SC) e Varia História (UFMG-MG) publicaram um artigo cada (1,7\%). A tabela abaixo apresenta um resumo dessa produção em periódicos nacionais: 


\begin{tabular}{|c|c|c|c|}
\hline Periódico & Instituição & $\begin{array}{l}\text { Número } \\
\text { de } \\
\text { Trabalhos }\end{array}$ & Percentual \\
\hline $\begin{array}{l}\text { Revista Latinoamericana de Psicopatologia } \\
\text { Fundamental }\end{array}$ & PUC-SP & 20 & $35,8 \%$ \\
\hline Histb́ria, Ciências, Saúde - Manguinhos & $\propto \propto C-$ Fiođuz/RJ & 12 & $21 \%$ \\
\hline Revista Mnemosine & IP - UERJ & 6 & $10,5 \%$ \\
\hline História Unisinos & Unisinos/RS & $@ 3$ & $5,2 \%$ \\
\hline $\begin{array}{l}\text { Memorandum - Memória e História em } \\
\text { Psicologia }\end{array}$ & UFMG/ USP & 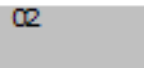 & $3,5 \%$ \\
\hline Revista de Psiquiatria Clínica & USP & $\mathscr{Q}$ & $3,5 \%$ \\
\hline $\begin{array}{l}\text { Revista Eletrônica Saúde Mental Alcool e } \\
\text { Drogas }\end{array}$ & $\begin{array}{l}\text { Escola de Enfermagem de Ribeirão } \\
\text { Preto }\end{array}$ & $œ$ & $3,5 \%$ \\
\hline Cadernos de Saúde Pública & $\begin{array}{l}\text { Escola Nacional de Saúde Pública } \\
\text { Sergio Arouca - Fiocruz/RJ }\end{array}$ & 01 & $1,7 \%$ \\
\hline Estudos Históricos & वDOC-FGVRJ & 01 & $1,7 \%$ \\
\hline Gazeta Médica da Bahia & UFEA & 01 & $1,7 \%$ \\
\hline $\begin{array}{l}\text { Interações - Estudos e Pesquisas em } \\
\text { Psicologia }\end{array}$ & Unimarco/SP & 01 & $1,7 \%$ \\
\hline Physis: Revista de Saúde Pública & INS - UEJ & 01 & $1,7 \%$ \\
\hline Psychiatry Online Brazil & & 01 & $1,7 \%$ \\
\hline Revista Baiana de Saúde Pública & SE/BA & 01 & $1,7 \%$ \\
\hline Revista Brasileira de Enfermagem & $\begin{array}{l}\text { Associação Brasileira de } \\
\text { Evfermagem }\end{array}$ & 01 & $1,7 \%$ \\
\hline Tempo e Argumento & UDECGSC & 01 & $1,7 \%$ \\
\hline Varia História & UFMG & 01 & $1,7 \%$ \\
\hline TOTAL DE ARTIGOS & & 57 & $100 \%$ \\
\hline
\end{tabular}

\section{Discussão}

O breve panorama da historiografia brasileira contemporânea a respeito da trajetória do saber psiquiátrico evidencia a pluralidade. A produção examinada reflete uma diversidade que se revela através da multiplicidade de objetos, abordagens e problemas, e mais, para além dessa, dos diferentes lugares a partir de onde essa História é escrita.

As perspectivas a partir das quais a História é construída dizem respeito tanto à organização interna dos procedimentos históricos, quanto à sua articulação com diferentes campos científicos e suas preocupações epistemológicas. Reconhecer a diversidade e a historicidade da própria História implica evidenciar a impossibilidade de compreender o sentido dos trabalhos analisados sem situá-los no seu universo historiográfico, ou seja, nas operações e práticas do seu lugar de produção. Muitos dos trabalhos da amostra são produzidos no âmbito específico de cursos de pós-graduação em História mesmo que por autores da área "Psi" (como psiquiatras e psicólogos) e por profissionais de outras áreas (como Ciências Sociais ou Enfermagem). Isso aponta para uma interessante interlocução entre disciplinas e nos remete à própria complexidade da construção do 
campo da saúde mental, que, para sua formalização, não prescinde do diálogo interdisciplinar e caminha na direção da transdisciplinaridade, ou seja, da emergência de um objeto comum, situado para além dos horizontes epistemológicos de investigação (NICOLESCU, 2005).

Face ao mapeamento efetuado, é possível identificar, em linhas gerais, a forma como a produção historiográfica toma os saberes e práticas de atendimento à saúde mental como objeto. Na análise das balizas temporais estabelecidas pelos estudos da amostra, constatouse que o momento de constituição e consolidação da Psiquiatria, entre 1890 e 1967, e, em especial, os últimos anos do século XIX e as primeiras décadas do século $X X$, foram os períodos, preferencialmente, pesquisados. Compreende-se que tal escolha por parte dos historiadores seja, necessariamente, multi-determinada: estado da documentação disponível, o interesse pela constituição do saber psiquiátrico, a atração pela especificidade do charme do fin-desiécle, além de um interesse por aspectos "genéticos" da questão, entre tantas justificativas possíveis. Constata-se, também, a escassez de estudos voltados a períodos mais recentes.

De forma similar, observou-se forte concentração geográfica dos objetos de pesquisa no eixo Sudeste-Sul, num contraste gritante com a falta de informações a respeito no restante do território nacional. A presença de instituições e de agências de fomento à pesquisa nesses pólos de maior produção certamente são fatores de impacto no desenvolvimento de projetos nessa área. Destacam-se as atividades da Casa de Oswaldo Cruz (Fiocruz), com sede no Rio de Janeiro, cujo curso de pós-graduação, juntamente com o periódico História, Ciências, Saúde - Manguinhos são responsáveis por cerca de $30 \%$ da produção nacional; e da Revista Latinoamericana de Psicopatologia Fundamental, periódico que, sozinho, publicou um terço de todos trabalhos identificados pela pesquisa.

O escasso nível de formalização tem sido apontado como peculiaridade do método historiográfico (Aróstegui, 2006; Veyne, 2008). A análise dos elementos metodológicos apontou que práticas nesse campo se caracterizam, em larga medida, pela observação documental escrita e utilização das técnicas tradicionais de análise temática de conteúdo. Tanto as técnicas de observação direta (entrevistas de História Oral), quanto os procedimentos mais complexos de análise, representam uma parcela bastante modesta das estratégias metodológicas empregadas. Em relação à tipologia das fontes, observa-se a utilização corrente de fontes não oficiais (documentos clínicos, imprensa, cartas dos internos e textos literários), que apontam para uma crescente valorização do caráter subjetivo da informação.

No que tange aos problemas abordados, temos um grande número de trabalhos cujas temáticas giram em torno da constituição do 
pensamento "psi" $(43,5 \%)$ e que apontam para uma preocupação epistemológica com a reconstrução da evolução dos conceitos e práticas terapêuticas. Constata-se, ainda, que a história institucional - ou asilar - continua contando com seu espaço, revelando-se um campo tradicional de estudo. Outro aspecto que chama a atenção é o interesse pelas múltiplas dimensões da constituição subjetiva das experiências da loucura, o que está de acordo com as discussões mais contemporâneas no campo das ciências sociais e humanas, que alicerçam os discursos dos movimentos de Reforma Psiquiátrica e luta antimanicomial, e que se dirigem para o contexto do resgate da dignidade e da cidadania dos sujeitos portadores de transtornos mentais (associando, assim, os debates da Reforma ao Movimento dos Direitos Humanos).

A História não pode ser escrita à margem do tempo presente, e a história recente da loucura, no Brasil, passa por uma viragem importante. A transformação proposta pela Reforma Psiquiátrica convoca os pesquisadores brasileiros a compreenderem a inscrição histórica da luta antimanicomial e demanda novas reflexões sobre o percurso das instituições psiquiátricas do país. Um dos problemas sempre presente - na análise histórica é a possibilidade de articulação e comparação entre o antes e o depois, e entre as partes localizadas e o todo. Para que essa compreensão mais ampla possa ser construída, pesquisas futuras deverão auxiliar no entendimento das nuances da trajetória da Psiquiatria por essas zonas cronológicas e geográficas, pouco conhecidas e, ainda, não valorizadas pela História.

O quadro constituído pelas pesquisas aqui apresentadas aponta para inovações temáticas e flexibilidade metodológica. Esse dado pode representar uma abertura para a superação de lacunas que ainda persistem no debate que toca tanto a implementação quanto os fundamentos da reforma à atenção à saúde mental no Brasil. Observando que o diálogo entre os diversos atores desse movimento é, tradicionalmente, prejudicado por defesas excludentes - tanto dos reformistas quanto dos representantes da contra-reforma, em defesas de teses, por vezes, contrárias, o que prejudica um verdadeiro diálogo de idéias e a possibilidade de construção de um quadro mais coeso e consistente no que se refere a políticas de atenção à saúde mental no país - podemos concluir que, a partir desse quadro de multiplicidade, a discussão deve tomar a direção necessária da transdisciplinaridade, envolvendo múltiplos atores e autores, bem como múltiplos olhares, construindo, assim, um campo macrodeterminado. Considera-se, com isso, que a construção de novo espaço para a atenção à saúde mental, no país, deve contemplar seus determinantes históricos, em sua diversidade e multiplicidade. 


\section{Referências Bibliográficas}

ALBERTI, V. Manual de história oral. 3a. ed. Rio de janeiro: Editora FGV, 2008. 235f.

ALMEIDA, A. A. S. Uma fábrica de loucos: Psiquiatria X Espiritismo no Brasil (1900 - 1950). 2007. Tese (Doutorado em História) Instituto de Filosofia e Ciências Humanas, Universidade Estadual de Campinas, Campinas.

ALMEIDA, A. A. S.; ODA, A. M. G. R.; DALGALARRONDO, P. O olhar dos psiquiatras brasileiros sobre os fenômenos de transe e possessão. Revista de Psiquiatria Clínica, v. 4, n. supl. 1, p. 3441, 2007.

ALMEIDA, F. M. Em memória a um pobre homem: a Psiquiatria de Dyonélio Machado em "Uma definição biológica do crime". Revista Latinoamericana de Psicopatologia Fundamental, São Paulo, v. 9, n. 4, 2006.

ALMEIDA, F. M. O Esboço de Psiquiatria Forense de Franco Rocha. Revista Latinoamericana de Psicopatologia Fundamental, São Paulo, v. 11, n. 1, p. 137-150, 2008.

ARANTES, M. A. Hospício de doutores. História, ciências, saúde Manguinhos, Rio de Janeiro, v. 15, n. 1, p. 49-63, 2007.

ARAÚJO JUNIOR, M. V.; MOREIRA, A.; ROCHA, B. Biografia de João Carlos Teixiera Brandão: de alienista a diretor da 1 a Escola de Enfermagem do Brasil. Revista Eletrônica Saúde Mental Álcool e Drogas, v. 5, n. 1, 2009.

ARÓSTEGUI, J. A pesquisa histórica: teoria e método. Tradução de Andrea Dore. Bauru: EDUSC, 2006. 592f.

BOARINI, M. L. A higiene mental e o saber instituido. Mnemosine, v. 3, n. 1, p. 3-17, 2007.

BORENSTEIN, M. S. et al. Terapias utilizadas no Hospital Colônia Sant'Ana: berço da psiquiatria catarinense (1914-1960). Revista Brasileira de Enfermagem, v. 60, n. 6, p. 665-669, 2007.

BORGES, V. T. A loucura herda um espaço deixado pela lepra: fragmentos de história oral com pacientes-moradores do Hospital Colônia Itapuã. História Unisinos, v. 10, n. 1, p. 99-106, 2006.

BORGES, V. T. Loucos (nem sempre) mansos da estância: controle e resistência no quotidiano do Centro Agrícola de Reabilitação (Viamão/RS, 1972-1982). 2007. Dissertação (Mestrado em História) - Instituto de Filosofia e Ciências Humanas, Universidade Federal do rio Grande do Sul, Porto Alegre.

BOTTI, N. C. L.; CASTRO, A. C. H. O. A.; COTTA, E. M. Primórdios da Psiquiatria no Centro-Oeste de Minas Gerais. Psychiatry on line Brasil, v. 14, n. 4, Abril 2009.

CARVALHO, S. M. M.; AMPARO, P. H. M. Nise da Silveira: a mãe da humana-idade. Revista Latinoamericana de Psicopatologia Fundamental, São Paulo, v. 9, n. 1, p. 126-137, 2006. 
CASTRO, A. D. C.; VARGAS, R. P. F. "Triste e bonito": a história dos saberes e práticas 'psi' na criação do Hospital Henrique Roxo. Mnemosine, v. 1, n. 2, p. 400-421, 2005.

CERTEAU, M. A escrita da história. Tradução de Maria de Lourdes Meneses. Rio de Janeiro: Forense, 2008.

COSTA, J. F. História da Psiquiatria no Brasil: um corte ideológico. 5a. ed. Rio de Janeiro: Garamond, 2007. 140f.

COSTA, L. A.; FONSECA, T. M. G. A disciplinarização dos espaços e das condutas: práticas urbanas para com a loucura. Menemosine, $v$. 3, n. 2, p. 248-273, 2007.

CUNHA, M. C. P. O Espelho do mundo: Juquery, a história de um asilo. 2a . ed. Rio de Janeiro: Paz e Terra, 1988. 217 p.

DALGALARRONDO, P. Estudos sobre religião e saúde mental realizados no Brasil: histórico e perspectivas atuais. Revista Psiquiatria Clínica, v. 34, supl 1, p. 25-33, 2007.

DALGALARRONDO, P.; GUTMAN, G.; ODA, A. M. G. R. Osório Cezar e Roger Bastide: as relações entre a arte, religião e psicopatologia. Revista Latinoamericana de Psicopatologia Fundamental, São Paulo, v. 10, n. 1, p. 101-117, 2007.

DIAZ, F. S. Os movimentos sociais na Reforma Psiquiátrica: o "novo" na história da psiquiatria no Brasil. 2008. Tese (Doutorado em História), Programa de Pós Graduação em História das Ciências e da Saúde, Casa Oswaldo Cruz- Fiocruz, Rio de Janeiro. EDLER, F. C. A medicina brasileira no século XIX: um balanço historiográfico. Asclepio. Revista de Historia de la Medicina y de la Ciencia, Madrid, v. 1, n. 2, p. 196-186, 1998.

ELIAS, N. Sobre o tempo. Tradução de Vera Ribeiro. 1a. ed. Rio de Janeiro: Zahar, 1998. 165f.

ENGEL, M. G. Sexualidades interditadas: loucura e gênero masculino. História, ciências, saúde - Manguinhos, Rio de Janeiro, v. 15, n. suplemento, p. 173-190, 2008.

FACCHINETTI, C.; RIBEIRO, A.; MUNOZ, P. As insanas do Hospício Nacional de Alienados (1900-1939). História, ciências, saúde Manguinhos, Rio de Janeiro, v. 15, n. suplemento, p. 231-242, 2008.

FACCHINETTI, C.; VENANCIO, A. T. Entre a psicanálise e a degenerescência: sexualidade e doença mental no início do século $X X$ no Brasil. Revista Latinoamericana de Psicopatologia Fundamental, São Paulo, v. 11, n. 1, p. 151-161, 2006.

FOUCAULT, M. História da loucura na idade clássica. Tradução de José Teixeira Coelho Netto. 2āa ed. São Paulo: Perspectiva, 1987.

O Nascimento da clínica. Tradução de Roberto Machado. 6ạ. ed. Rio de Janeiro: Forense, 2006a.

O poder psiquiátrico. Tradução de Eduardo Brandão. 1a. ed. São Paulo: Martins Fontes, 2006b. 
FUNARI, P. P.; SILVA, G. J. D. Teoria da história. 1a. ed. São Paulo: Brasiliense, 2008.

GONÇALVES, M. D. S.; EDLER, F. C. Os caminhos da loucura na Corte Imperial: um embate historiográfico acerca do funcionamento do Hospício Pedro II de 1850 a 1889. Revista Latinoamericana de Psicopatologia Fundamental, São Paulo, v. 12, n. 2, p. 393-410, 2009.

GUTMAN, G. Raça e Psicanálise no Brasil. O ponto de origem: Arthur Ramos. Revista Latinoamericana de Psicopatologia Fundamental, São Paulo, v. 10, n. 4, p. 711-728, 2007.

JABERT, A. Formas de administração da loucura na Primeira República: o caso do estado do Espírito Santo. História, ciências, saúde - Manguinhos, Rio de Janeiro, v. 12, n. 3, p. 693-716, 2005.

De médicos e médiuns: medicina, espiritismo e loucura no Brasil da primeira metade do século XX. 2008. Tese (Doutorado em História) - Programa de Pós Graduação em História das Ciências e da Saúde, Casa de Oswaldo Cruz/Fiocruz, Rio de Janeiro.

J ACÓ-VILELA, A. M.; ESCH, C. A.; COELHO, D. A. M; REZENDE, M. S. Os estudos médicos no Brasil no século XIX: contribuições à Psicologia. Memorandum, v. 7, p. 138-150, 2004.

J ACÓ-VILELA, A. M.; ESPÍRITO SANTO, A. A. E; PEREIRA, V. F. Medicina legal nas teses da Faculdade de Medicina do Rio de Janeiro (1830-1930): o encontro entre Medicina e Direito, uma das condições de emergência da Psicologia Jurídica. Interações, v. 10, n. 19, p. 934, 2005.

JACOBINA, R. R. O silêncio dos inocentes III: o cuidado aos psicopatas e degenerados no Hospício São João de Deus. Revista Baiana de Saúde Pública, v. 28, n. 1, p. 50-64, 2004.

J ACOBINA, R. R.; GELMAN, E. A. Juliano Moreira e a Gazeta Médica da Bahia. História, Ciências, Saúde - Manguinhos, Rio de Janeiro, v. 15, n. 4, p. 1077-1097, 2008.

JAEGER, R. L.; FONSECA, T. M. G.; SANCHES, G. S. Invenção e clausura no hospital psiquiátrico. Mnemosine, v. 2, n. 2, p. 56-63, 2006.

MACHADO, R.; et al. Danação da norma: Medicina social e constituição da psiquiatria no Brasil. 1ạ. ed. Rio de Janeiro: Graal, 1978.

MAGNANI, M. C. A. O. O hospício de Diamantina ( 1889 - 1906). 2004. Dissertação (Mestrado em História) - Programa de Pós Graduação em História das Ciências e da Saúde, Casa de Oswaldo Cruz/ Fiocruz, Rio de Janeiro.

MELO, W. Ulysses Pernambucano: o enamorado da liberdade. Mnemosine, v. 1, n. 0, p. 185-192, 2004.

MESSAS, G. P. O espírito das leis e as leis do espírito: a evolução do pensamento legislativo brasileiro em saúde mental. História, ciências, saúde - Manguinhos, v. 15, n. 1, p. 65-98, 2008. 
NICOLESCU, B. O manifesto da transdiciplinaridade. 3a Ed. São Paulo: Triom, 2005.

O'BRIEN, P. A história da cultura de Michel Foucault. In: HUNT, L. A nova história cultural. Tradução de J efferson Luiz Camargo. 2a a . ed. São Paulo: Martins Fontes, 2006. Cap. I, p. 33-62.

ODA, A. M. G. R. Apresentação a "Insânia loquaz" (J obim, 1831) e a "Reflexos sobre o trânsito livre dos doidos pelas ruas da cidade do Rio de Janeiro" (Sigaud, 1835). Revista Latinoamericana de Psicopatologia Fundamental, São Paulo, v. 8, n. 3, p. 554-556, 2005.

O banzo e outros males: o páthos dos negros escravos na Memória de Oliveira Mendes. Revista Latinoamericana de Psicopatologia Fundamental, São Paulo, v. 10, n. 2, p. 346-361, 2007.

ODA, A. M. G. R.; DALGALARRONDO, P. O início da assistência aos alienados no Brasil ou importância e necessidade de estudar a história da psiquiatria. Revista Latinoamericana de Psicopatologia Fundamental, São Paulo, v. 7, n. 1, p. 128-141, 2004.

História das primeiras instituições para alienados no Brasil. História, ciências e saúde - Manguinhos, v. 12, n. 3, p. 9831010, 2005.

ODA, A. M. G. R.; PICCININI, W. Dos males que acompanham o progresso do Brasil: a psiquiatria comparada de Juliano Moreira e colaboradores. Revista Latinoamericana de Psicopatologia Fundamental, São Paulo, v. 8, n. 4, p. 788-793, 2005.

ODA, A. M. R. G. Escravidão e nostalgia no Brasil: o banzo. Revista latinoamericana de Psicopatologia Fundamental, São Paulo, v. 11, n. 4 (supl), p. 735-761, 2008.

OLIVEIRA, S. V.; ODA, A. M. G. R. O suicídio de escravos em São Paulo nas últimas duas décadas da escravidão. História, ciências, saúde - Manguinhos, Rio de Janeiro, v. 15, n. 2, p. 371-388, 2008. OLIVEIRA, C. F. A.; RÊGO, S. R. M. Desde Pinel a Juliano Moreira: os tratamentos do alienismo no Brasil. Psychiatry on line Brasil, v. 14, n. 12, dezembro 2009.

OLIVEIRA, C. F. A.; RÊGO, S. R. M.; SILVA, D. J. N. História da Psiquiatria no Brasil: que história é essa? Psychiatry on line Brasil, v. 12, n. 11, novembro 2007.

OUYAMA, M. Uma máquina de curar: o hospício Nossa Senhora da Luz em Curitiba e a formação da tecnologia asilar (final do século XIX e início do século XX). 2006. Tese (Doutorado em História) - Setor de Ciências Humanas, Letras e Artes, Universidade Federal do Paraná, Curitiba.

PAIVA, I. L.; YAMAMOTO, O. H. Em defesa da reforma psiquiátrica: por um amanhã que há de nascer sem pedir licença. História, ciências, saúde - Manguinhos, v. 14, n. 2, p. 549-569, 2007. 
PAULIN, L. F.; TURATO, E. R. Antecedentes da reforma psiquiátrica no Brasil: as contradições dos anos 1970. História, ciências, saúde - Manguinhos, v. 11, n. 2, p. 241-258, 2004.

PEREIRA, M. E. C. Ulysses Pernambucano e a questão da "Higiene mental". Revista Latinoamericana de Psicopatologia Fundamental, São Paulo, v. 8, n. 1, p. 123-129, 2005.

PEREIRA, M. E.; GUTMAN, G. Primitivo e loucura, ou o inconsciente e a psicopatologia segundo Arthur Ramos. Revista Latinoamericana de Psicopatologia Fundamental, São Paulo, v. 10, n. 3, p. 517525, 2007.

PEREIRA, R. C. Políticas de saúde mental no Brasil: o processo de formulação da lei de reforma psiquiátrica (10.216/01). 2004. Tese (Doutorado em Saúde Pública) - Escola Nacional de Saúde Pública Sérgio Arouca, Fundação Oswaldo Cruz, Rio de Janeiro.

PESSOTTI, I. A loucura e as épocas. 2a . ed. Rio de Janeiro: Editora 34, 1995. 207f. $\overline{1} \overline{9} \overline{6}$.

O século dos manicômios. 1a. ed. São Paulo: Editora 34,

Os Nomes da Loucura. 1a. ed. São Paulo: Editora 34, 1999.

PICCININI, W. O Asilo Terapêutico, uma experiência brasileira. (Apreciação do Relatório do Dr. Carlos Lisbôa à Direção da Santa Casa de Misericórdia de Porto Alegre, em 1884). (I). Psychiatry on line Brasil, v. 14, n. 5, março 2009.

. O Asilo Terapêutico, uma experiência brasileira. (Apreciação do Relatório do Dr. Carlos Lisbôa à Direção da Santa Casa de Misericórdia de Porto Alegre, em 1884). (II). Psychiatry on line Brasil, v. 14, n. 6, junho 2009.

- Notas para a História da Associação Brasileira de Psiquiatria.

Psychiatry on line Brasil, v. 15, n. 3, março 2010.

PICCININI, W.; ODA, A. M. G. R. História da Psiquiatria: a loucura e os legisladores. Psychiatry on line Brasil, v. 11, n. 3, março 2006.

POMBO, R. M. R. A nova política de saúde mental: entre $O$ precipício e paredes sem muros (Uberlândia 1984-2006). 2007. Dissertação (Mestrado em História) - Programa de Pós-Graduação em História, Universidade Federal de Uberlândia, Uberlândia.

RIBEIRO, R. A. Almas Enclausuradas: práticas de intervenção médica, representações culturais e cotidiano no Sanatório Espírita de Uberlândia. 2006. Dissertação (Mestrado em História) - Programa de Pós-Graduação em História, Universidade Federal de Uberlândia, Uberlândia.

RIOS, V. D. B. O 'Asylo', uma necessidade indeclinável de organização social: indagações em torno do questionário de internamento de Asilo São J oão de Deus. História, ciências, saúde - Manguinhos, Rio de Janeiro, v. 15, n. 4, p. 989-1012, 2008. ROCHA, N. M. D.; TRANQUILLI, A. G.; LEPIKSON, B. B. A faculdade de Medicina da Bahia no século XIX: a preocupação com aspectos de 
saúde mental. Gazeta Médica da Bahia, v. 74, n. 2, p. 103-126, 2004.

SANTOS, N. M. W. Histórias de sensibilidades: espaços e narrativas da loucura em três tempos: Brasil, 1905/1920/1937. 2005. Tese (Doutorado em História) - Instituto de Filosofia e Ciências Humanas, Universidade Federal do Rio Grande do Sul, Porto Alegre.

De médico e louco. as fronteiras entre discursos. Revista Latinoamericana de Psicopatologia Fundamental, São Paulo, v. 9, n. 2, p. 339-361, 2006a.

SANTOS, N. M. W. Nas "entrelinhas" da história: sensibilidades e exclusão em narrativas da loucura. História Unisinos, v. 10, n. 1, p. 80-89, 2006b.

SILVA, R. P. Medicina, educação e psiquiatria para a infância: o Pavilhão-Escola Bourneville no início do século XX. Revista Latinoamericana de Psicopatologia Fundamental, São Paulo, v. 12, n. 1, p. 195-208, 2009.

SILVA, R. P. D. Medicina, educação e psiquiatria para a infância: - pavilhão-escola Bourneville no início do século XX. 2008. Dissertação (Mestrado em História) - Programa de Pós Graduação em História das Ciências e da Saúde, Casa de Oswaldo Cruz - Fiocruz, Rio de Janeiro.

SILVEI RA, R. D. Projeto Lopes Rodrigues: continuidades e rupturas nas conexões entre ensino psiquiátrico e prática assistencial em Minas Gerais (1920-1930). 2008a. Tese (Doutorado em Educação) Faculdade de Educação, Universidade Federal de Minas Gerais, Belo Horizonte.

. A correspondência entre Juliano Moreira e Hermelindo Lopes Rodrigues: as relações de um mestre e seu discípulo na constituição do campo psiquiátrico em Minas Gerais. Revista Latinoamericana de Psicopatologia Fundamental, São Paulo, v. 11, n. 2, p. 315328, 2008b.

. Psicanálise e psiquiatria nos inícios do século XX: a apropriação do conceito de esquizofrenia no trabalho de Hermelino Lopes Rodrigues. Revista Latinoamericana de Psicopatologia Fundamental, São Paulo, v. 12, n. 3, p. 582-596, 2009.

SOUZA, R. S.; JACÓ-VILELA, A. M. Paixões e afetos: uma análise sobre conceitos e apropriações em tese de medicina do século XIX. Memorandum, v. 15, p. 35-51, 2008.

SZASZ, T. S. A fabricação da loucura: um estudo comparativo entre a Inquisição e o movimento de Saúde Mental. Tradução de Dante Moreira Leite. 2a . ed. Rio de Janeiro: Zahar, 1978.

TARSO, V. N. S. D. Joanna de Sá: medicina política e moral nas páginas de $\mathrm{O}$ Monitor. História, ciências, saúde - Manguinhos, v. 15, n. 4, p. 973-988, 2008.

VASCONCELLOS, C. T. D. D. V.; VASCONCELLOS, S. J. L. A doença mental feminina em Porto Alegre, Rio Grande do Sul, Brasil (1870- 
1910). Cadernos de Saúde Pública, v. 23, n. 5, p. 1041-1049, 2007.

VASCONCELOS, E. Mundos paralelos, até quando? Os psicólogos e o campo da saúde mental pública no Brasil nas duas últimas décadas. Mnemosine, v. 1, n. 0, p. 73-90, 2004.

VENANCIO, A. T. Doença mental, raça e sexualidade nas teorias psiquiátricas de Juliano Moreira. Physis: Revista Saúde Coletiva, v. 14, n. 2, p. 283-301, 2004.

VENANCIO, A. T. A. As faces de Juliano Moreira: luzes e sombras sobre seu acervo pessoal e suas publicações. Estudos históricos, v. 36, p. 59-73, 2005.

VENANCIO, A. T.; FACCHINETTI, C. "Gentes provindas de outras terras: ciência psiquiátrica, imigração e nação brasileira. Revista Latinoamericana de Psicopatologia Fundamental, São Paulo, v. 8, n. 2, p. 357-363, 2005.

VEYNE, P. Como se escreve a história. Tradução de Alda Baltazar e Maria Auxiliadora Kneipp. 4ae ed. Brasília: UNB, 2008.

VIDAL, L. V. D. M. V.; AMORIN, W. M. D. Reconhecimento do psiquiatra Jurandir Manfredini entre estudantes da Escola de Enfermagem Alfredo Pinto, 1954-1955. Revista Eletrônica Saúde Mental Álcool e Drogas, v. 4, n. 1, 2008.

WADI, Y. M. Palácio para guardar doidos. Porto Alegre: Editora da Universidade, 2002.

WADI, Y. M. "Um lugar todo seu?": paradoxos do viver em uma instituição psiquiátrica. Varia história, Belo Horizonte, v. 32, n. 1, p. 75-101, 2004.

WADI, Y. M. A escrita epistolar no hospício: documento médico, documento histórico. Revista Latinoamericana de Psicopatologia Fundamental, São Paulo, v. 8, n. 1, p. 137-149, 2005.

WADI, Y. M. Experiências de vida, experiências de loucura: algumas histórias sobre mulheres internas no Hospício São Pedro (Porto Alegre, RS, 1884-1923). História Unisinos, v. 10, n. 1, p. 65-79, 2006.

WADI, Y. M. Uma história da loucura no tempo presente: os caminhos da assistência e na reforma psiquiátrica no Estado do Paraná. Tempo e argumento, n.1, p. 1-35, 2009.

\section{Endereço para correspondência}

Andrea de Alvarenga Lima

Departamento de Psicologia, Universidade Federal do Paraná, Praça Santos Andrade, 50, Sala 215, Ala Alfredo Buffren, CEP 8006-240, Curitiba - PR, Brasil

Endereço eletrônico: alvarenga.lima@gmail.com

Adriano Furtado Holanda

Departamento de Psicologia, Universidade Federal do Paraná, Praça Santos Andrade, 50, Sala 215, Ala Alfredo Buffren, CEP 8006-240, Curitiba - PR, Brasil

Endereço eletrônico: aholanda@yahoo.com 
Recebido em: 25/02/2010

Aceito para publicação em: 13/04/2010

Acompanhamento do processo editorial: Ana Maria Jacó Vilela

\section{Notas}

*Doutor em Psicologia pela Universidade Federal do Paraná - UFPR. 